\title{
O TESTEMUNHO COMO FONTE DE CONHECIMENTO
}

\author{
Lorrayne Bezerra Vasconcelos Colares \\ Graduanda em Filosofia na Universidade de Brasília - UnB
}

\section{RESUMO}

Tendo grande importância em diversos aspectos da nossa vida, o testemunho está presente desde quando pedimos informação a alguém ou meramente acreditamos em nossas datas de nascimento. Porém, durante um enorme período na história da epistemologia, sua importância como fonte epistêmica geradora de conhecimento foi negligenciada. Analisando essa tradição e suas críticas, em primeiro lugar, analisaremos o trabalho de David Hume, no qual encontramos o primeiro ataque à noção de testemunho como fonte transmissora de informação e geradora de conhecimento, e, além disso, o estabelecimento das bases do individualismo epistemológico. Em seguida, serão expostos alguns dos mais recentes trabalhos a respeito da justificação testemunhal que se caracterizam como alternativas à visão humeana, como o não-reducionismo de C. A. J. Coady, o dualismo de Jennifer Lackey, o comunitarismo de Martin Kusch e o confiabilismo de Sanford C. Goldberg.

Palavras-chave: Testemunho. Conhecimento. Crença. Epistemologia. Fonte epistêmica.

\begin{abstract}
Having a huge significance in various aspects of our lives, testimony is present when you ask for information from someone or merely believe in our birth date. However, during an enormous period in the history of epistemology, his significance as a generative epistemic source of knowledge has been neglected. Analyzing this tradition and its critics, in the first place, we analyze the work of David Hume, in which we find the first attack on the notion of testimony as source of information and generating knowledge and, furthermore, the establishment of the foundations of epistemological individualism. It will subsequently be exposed some of the most recent studies about testimonial justification characterized as an alternative to the Humean view, as C. A. J. Coady's non-reductionism, Jennifer Lackey's dualism, Martin Kusch's communitarianism and Sanford C. Goldberg's reliabilism.
\end{abstract}

Key-words: Testimony. Knowledge. Belief. Epistemology. Epistemic Source. 


\section{Introdução}

Uma das principais preocupações dos epistemólogos durante toda a história da filosofia sempre foi a de definir o que é o conhecimento. Tal empreendimento remonta no mínimo a Platão e se tornou moda nas discussões filosóficas do século XX, particularmente no que diz respeito à tentativa de fornecer uma definição que incorporasse tanto as ideias de verdade e crença e que distinguisse mera crença verdadeira de conhecimento.

Apesar do enorme esforço concentrado nesse assunto, a tradição filosófica, na sua maior parte, ou ignorou completamente o testemunho, ou foi superficial e desdenhosa em relação ao assunto. Epistemólogos modernos estudaram incansavelmente a natureza e o papel de outras fontes epistêmicas, tais como a memória, a percepção, o raciocínio indutivo e dedutivo, mas não dedicaram praticamente nenhuma análise e argumentação à justificação testemunhal.

Entretanto, nas últimas décadas, inúmeros estudiosos começaram a considerar positivamente a contribuição do testemunho para muito do que sabemos e acreditamos. $\mathrm{O}$ lugar do testemunho como uma fonte epistêmica, a partir da qual podemos adquirir conhecimento, começou a ser repensado e inúmeras teorias de justificação testemunhal foram formuladas. O presente artigo tem como objetivo analisar o porquê dessa tradição de negligência para com o testemunho, expor o declínio da tradição individualista em detrimento de uma visão mais social do testemunho e, além disso, tentar elucidar até que ponto essas novas considerações delineiam um campo de estudos tão rico no qual ainda há muito a ser estudado.

\section{David Hume: Reducionismo e individualismo epistemológico}

David Hume, um dos nomes mais importantes da filosofia moderna, foi um dos poucos filósofos que apresentou uma consideração sobre o testemunho, consideração esta de tal importância que mesmo as discussões atuais a respeito do reducionismo continuam tomando suas ideias como ponto de partida. Sua visão sobre esse assunto está presente no seu ensaio sobre os milagres, na seção $\mathrm{X}$ da sua obra Investigações Sobre o Entendimento Humano. Seu objetivo, em tal seção, é mostrar que a crença nos milagres não é fundamentada, uma vez que tal crença se baseia no testemunho para afirmar uma interrupção no 
funcionamento das leis naturais. Ele fez um vigoroso ataque ao testemunho como forma de aquisição de conhecimento, comparando-o desfavoravelmente à percepção sensorial, fonte epistêmica na qual se baseiam as proposições da ciência. E mais, sua visão consagrou-se como que um princípio de individualismo epistemológico, expresso na ideia de que, para se saber algo com fundamento, é preciso, por si mesmo, ter acesso direto à ocorrência empírica à qual esse conhecimento se refere ou ser capaz de desenvolver pessoalmente o raciocínio que levou à conclusão defendida. Tal visão foi denominada pela posterioridade como reducionismo epistemológico, pois aceita que podemos tomar como conhecido o que nos é apresentado nos casos que dependem do testemunho, mas afirma que a nossa confiança nele é justificada em termos de outras formas supostamente mais fundamentais de evidências ou fontes epistêmicas, isto é, as próprias observações do indivíduo e as inferências que ele faz a partir delas.

Na primeira parte da seção $X$, Hume afirma que a experiência é nosso único guia ao raciocinar sobre questões de fato, porém ela é um guia passível de falhas. Sendo assim, ao fazermos raciocínios relativos a questões de fatos, nos submetemos aos mais diversos graus de confiança, e nos inclinamos a uma dada conclusão de acordo com a sua probabilidade. Aplicando esse princípio ao caso particular do testemunho, Hume reconhece a importância do testemunho e afirma que "nenhuma espécie de raciocínio é mais comum, mais útil e mesmo mais necessária à vida humana que o que deriva do relato das pessoas e dos depoimentos de espectadores e testemunhas oculares" (HUME, 2004, p. 156). No entanto, para ele, toda a nossa confiança em qualquer tipo de argumento testemunhal deriva de nossas observações da veracidade do testemunho e da conformidade habitual entre os relatos de testemunhas e os fatos. Sendo assim, a razão pelo qual damos crédito a testemunhas "não deriva de qualquer conexão que percebamos a priori entre o testemunho e a realidade, mas de estarmos acostumados a encontrar uma concordância entre essas coisas" (HUME, 2004, p. 158). Extraise disso que quando um fato relatado é de um tipo que raramente se apresentou à nossa observação, surge assim uma controvérsia entre duas experiências antagônicas, na qual uma destrói a outra no que diz respeito à força, e a superior atua em nossas mentes pela força resultante de tal conflito.

Em seguida, Hume define um milagre como uma violação das leis da natureza. Ele define como uma máxima que:

nenhum testemunho é suficiente para estabelecer um milagre, a menos que seja de um tipo qual que a sua falsidade fosse ainda mais milagrosa que o 
fato que se propõe a estabelecer. E ainda assim ocorre uma destruição mútua de argumentos, de modo que o mais forte só nos oferece uma confiança apropriada ao grau de força que resta após subtrair-se dele o mais fraco (HUME, 2004, 161).

Ou seja, Hume está dizendo que a explicação da falsidade do relato é, em geral, mais verossímil ou provável que a verdade de tal relato. Se não fosse, então poderíamos aceitar o milagre, mas é difícil que isso venha a acontecer.

Já na segunda parte, Hume apresenta quatro razões na tentativa de provar que acontecimentos milagrosos demonstrados em evidências tão plenas nunca ocorreram. Primeiro, porque a história não nos apresenta nenhum milagre atestado por um número suficiente de homens de bom senso, educação, saber, integridade, crédito e reputação tão indubitáveis, nem que seja realizado de maneira tão pública que não pudesse ser desmascarado. Segundo, que temos tendência em acreditar em acontecimentos milagrosos devido à emoção agradável proveniente da surpresa e do assombro que eles nos causam. Terceiro, que a maioria dos relatos sobrenaturais e miraculosos resulta de "nações ignorantes e bárbaras" ou, em casos de povos civilizados, de "ancestrais ignorantes e bárbaros" (HUME, 2004, p. 165). E, em quarto e último lugar, que não há relato algum desses prodígios "que não sofra a oposição de um número infinito de testemunhas, de modo que não apenas o milagre destrói o crédito do relato, mas o próprio relato destrói-se a si mesmo" (HUME, 2004, p. 168). Hume ilustra esse quarto ponto fazendo uma poderosa crítica às religiões, segundo a qual um milagre propagandeado por uma religião, cujo objetivo é o de consolidar tal religião, tem o poder de derrubar todos os outros sistemas religiosos, e o crédito dos milagres produzidos por eles.

Prosseguindo, ele conclui que, no conjunto:

parece que nenhum testemunho em favor de um milagre de qualquer tipo jamais chegou sequer a torná-lo provável, quanto menos a constituir uma prova de sua ocorrência, e que, mesmo supondo-se que chegasse a fazê-lo, seria contraditado por outra prova, derivada da própria natureza do fato que ele se esforça por estabelecer" (HUME, 2004, p. 178).

E, assim, podemos assumir como máxima que nenhum testemunho pode ter força suficiente para provar um milagre e torná-lo uma base legítima para fundar algum tipo de sistema religioso. 


\section{Coady e o não-reducionismo}

C. A. J. Coady afirma que começou a pensar sobre o status epistemológico do testemunho na década de 60, quando estava escrevendo uma tese sobre questões na teoria da percepção. Seu importante livro Testimony: A Philosophical Study, publicado em 1992, foi um marco na história da revolução externalista que ocorreu na epistemologia nas últimas décadas. Coady não só reconheceu que nossa confiança na palavra dos outros é fundamental à própria ideia de uma séria atividade cognitiva, mas notou que o testemunho era uma paisagem epistemológica proeminente e pouco explorada pela tradição, diferentemente da razão, da memória, da indução e da dedução, apesar do testemunho, à primeira vista, pertencer a essa lista de fontes epistêmicas. Pois, segundo ele, se numa determinada investigação perguntamos algo como “"Por que você acredita nisso?' ou 'Como você sabe disso?', a resposta 'Ele me disse' pode ser tão apropriada quanto 'Eu vi', 'Eu me lembro', 'Segue-se disso' ou 'Normalmente acontece assim"' (COADY, 1992, p. 6, tradução nossa).

Coady defende que é preciso negar a sugestão de que tal negligência do testemunho é justificada pelo fato de realmente ter um papel insignificante, ou pouco significativo, na formação da crença racional, pois tal sugestão não se sustenta. Quando afirmamos que temos $\mathrm{x}$ anos de idade, que nascemos uma determinada data, que um determinado número corresponde a nosso número do passaporte, entre outros, sabemos que nenhum desses fatos são de nossa observação individual ou de nossa memória ou de nossa inferência, eles são baseados na palavra dos outros. Além disso, "esta confiança não se limita ao cotidiano ou ao meramente prático, (...) uma vez que atividades teóricas altamente desenvolvidas também são marcadas por uma confiança no testemunho" (COADY, 1992, p. 8, tradução nossa). Para Coady, o estudo da história, das ciências sociais, das ciências físicas e até mesmo das ciências mais abstratas, como a astronomia e a física teórica, são muito dependentes do testemunho. E mais, pois o cientista confia no testemunho de seus colegas e outros observadores e argumenta a partir de, e pressupondo, numerosas observações e experimentos que ele não apresentou a si mesmo. Além disso, ele depende das experiências, cálculos, observações, teorias e até mesmo de outros na condução de sua própria investigação, para chegar às suas próprias conclusões. Sendo que ainda, muitas vezes, o que os outros nos dizem serve como uma importante corroboração para o que já havíamos descoberto por nós mesmos. 
A visão de Coady, em oposição ao reducionismo de Hume e outros autores, é chamada pela literatura de não-reducionismo ou fundamentalismo epistemológico ${ }^{1}$. Tal visão afirma que o testemunho nos dá conhecimento, mas se recusa a aceitar que nossa confiança no testemunho pode ser justificada em termos de algumas outras fontes supostamente mais fundamentais do conhecimento. A confiança no testemunho deve ser considerada como fundamental para a justificação da crença da mesma maneira como a percepção, a memória e a inferência o são.

Para sustentar sua posição, Coady faz uma importante análise e crítica da tradição epistemológica reducionista. Ele reconhece a importância de Hume por ter sido um dos poucos filósofos a apresentar uma consideração sobre o assunto e por ter reconhecido a importância e utilidade do testemunho à vida humana. Porém, para ele, a teoria humeana:

constitui uma redução do testemunho como um meio de prova ou de apoio ao status de uma espécie (...) de inferência indutiva. E, novamente, na medida em que inferência indutiva é reduzida por Hume a espécies de observações e consequências resultantes dessas observações, então o testemunho encontra o mesmo destino (COADY, 1992, p. 79, tradução nossa).

E essa é uma visão que Coady pretende contestar, e para isso ele convenientemente rotula e abrevia essa tese reducionista como TR. Sua crítica começa notando uma ambiguidade no uso de termos como experiência e observação na declaração humeana da TR. Segundo Hume, nós apenas confiamos em testemunhos porque a experiência tem nos mostrado que eles são confiáveis. Porém, Coady defende que onde experiência significa observação individual isso parece claramente falso, visto que nossa confiança no testemunho vai corretamente além de qualquer coisa que poderia ser justificada em termos de observações individuais; e onde significa experiência comum, ou seja, a confiança nas observações dos outros, é certamente uma petição de princípio.

Coady tenta, então, tirar a segunda parte da ambiguidade. Segundo ele, encontramos Hume falando da nossa experiência de conjunção constante e regular e sabemos que ele recorre à frases desse tipo para se referir à experiência comum da humanidade, como uma

1 C. A. J. Coady não é o primeiro a defender tal posição, essa posição já pode ser encontrada nos escritos de Thomas Reid, contemporâneo de David Hume. Entretanto, atualmente Coady é visto como um dos principais teóricos defensores do não-reducionismo. 
fusão de observação pessoal e comunitária. Coady cita um trecho encontrado no Tratado da Natureza Humana, onde Hume diz:

Eu recebo uma carta e, ao abri-la, percebo pela caligrafia e pela assinatura ter sido enviada por um amigo, que diz estar a duzentas léguas de distância. É evidente que eu nunca poderia dar conta deste fenômeno conforme a minha experiência de outros casos, sem desdobrar em minha mente todo o mar e continente que nos separam, e sem supor os efeitos e a existência contínua de correios e barcas, de acordo com a minha memória e observação (1739-1740, apud COADY, 1992, p. 81, tradução nossa).

Para Coady, Hume usa a expressão minha observação quando não tem o direito de fazê-lo, pois provavelmente não há pessoa alguma que tenha observado pessoalmente o caminho completo de uma carta a partir do momento em que ela deixa a mão do remetente até momento em que atinge o seu destino. Sua crença nisso é dependente de uma complicada rede de testemunhos e de inferências. Logo, a posição de Coady é que essa teoria é claramente falsa, pois seria absurdo sugerir que, individualmente, temos feito algo parecido com a quantidade de trabalho de campo que ela requer, pois isso exigiria um grande número de observações.

Em seguida, Coady se volta a uma diferente, e talvez mais decisiva, dificuldade para esse tipo de abordagem. Pois, discordando da tese de Hume, Coady defende que:

Nós podemos ter descoberto que não há conformidade nenhuma entre testemunho e realidade. A posição de Hume requer a possibilidade de que nós isolamos claramente os relatos que as pessoas fazem sobre o mundo para compará-los com nossa observação pessoal do estado real do mundo e, com isso, encontrarmos uma correlação alta, baixa ou inexistente entre eles. Mas não é de forma clara que podemos entender esta sugestão (COADY, 1992, p. 85 , tradução nossa).

Coady conclui questionando se o colapso do projeto reducionista de Hume e a violação do ideal associado de conhecimento autônomo deixa espaço para qualquer aspiração a um grau forte de autonomia cognitiva. Ele defende que apesar dessa herança forte que o individualismo nos deixou, tanto na esfera intelectual como na prática, nosso compromisso para com ele deve ser evitado. Além disso, o conhecedor autônomo não precisa renunciar absolutamente da sua confiança e dependência para com a palavra dos outros, mas sim deve utilizá-las como instrumentos epistêmicos para alcançar uma verdadeira postura crítica e independência viável de perspectivas. Para Coady, a imagem humeana de testemunho sustenta um ideal de autonomia epistêmica (ou, pode-se pensar até mesmo num ideal de egoísmo epistêmico) que é ilusório, e que tem sido particularmente prejudicial. Todavia, "uma vez que 
este for abandonado, estamos livres para construir um conceito mais realista e útil de pensar" (COADY, 1992, p. 100, tradução nossa).

Outro ponto de extrema importância abordado por Coady é que a confiança no testemunho deve ser considerada como fundamental para a justificação da crença no mesmo tipo de modo como a percepção, a memória e a inferência o são. Ele, então, examina as semelhanças e as diferenças entre o testemunho e as outras fontes de informação, e como estas se manifestam na gramática lógica de nossos conceitos e nos nossos modos naturais de pensamento e investigação. Segundo ele, estaremos seguindo um caminho reducionista se pensarmos que o conhecimento direto só pode ser apropriadamente invocado quando somos confrontados com o conteúdo de uma experiência. Porém, ele afirma que uma dificuldade surge da ideia de que o conhecimento testemunhal possa ser direto, ou seja, a dificuldade de que pode ser instado que uma pessoa racional não acredita em toda e qualquer coisa que lhe é dita, que o "seu consentimento deve ser mediado por uma consideração sobre a veracidade do testemunho, sua confiabilidade, sua probabilidade, e assim por diante" (COADY, 1992, p. 143, tradução nossa). Coady defende que esse tipo de argumento é certamente falacioso, tendo em vista que nas nossas relações normais com os outros recolhemos informações sem essa preocupação de inferir a aceitabilidade das comunicações a partir de premissas sobre a honestidade, confiabilidade, probabilidade, etc., de nossos comunicadores. Segundo ele:

Eu ligo para a empresa de telefonia por ser incapaz de localizar minha conta e uma voz anônima me conta que se trata de 165 dólares com o vencimento em 15 de junho. Nenhum pensamento de determinar a veracidade e a confiabilidade da testemunha me ocorre, assim como, dado o valor total estar dentro de limites toleráveis, fazer o balanço das probabilidades não figura em minha aceitação (COADY, 1992, p. 143, tradução nossa).

Ou seja, você não precisa de uma razão para aceitar que o relato é veraz, confiável e provável, mas isto é assumido e basta que você não tenha uma razão contrária a esta assunção. Coady defende a ideia de que, no que diz respeito às questões de confiabilidade e honestidade de uma testemunha, nós podemos muitas vezes afirmar que o mecanismo do testemunho está funcionando adequadamente, assim como consideramos que os mecanismos de percepção ou de memória estão ou não funcionando incorretamente.

Para Coady, apesar das diferenças entre percepção, memória e testemunho, todas essas fontes fornecem técnicas ou mecanismos para a aquisição de crenças verdadeiras e o testemunho tem todo o direito ao status de uma importante fonte de conhecimento. Porém, há a incômoda suspeita de que, no entanto, o conhecimento perceptual é necessariamente mais 
básico do que o testemunhal, que o dar e receber de testemunho só é possível através de percepção. "Devemos ouvir as mensagens ou vê-las por escrito para que haja testemunho, e nosso informante deve se lembrar de que ele viu ou ouviu" (COADY, 1992, p. 146, tradução nossa). Além disso, mesmo tendo em conta complexas cadeias de testemunho, a fonte de informação testemunhal deve finalmente ser de alguma forma perceptual ou intelectual. Dessa maneira, então, o testemunho precisa de uma origem epistêmica distinta de si e necessita de um meio epistêmico distinto de si. Mas, segundo Coady, esses fatos não demonstram que o testemunho tem uma legitimidade epistêmica inferior à percepção, eles apenas nos ajudam a lembrar da centralidade da percepção e esta centralidade não concede nenhuma prioridade redutora ou superioridade epistemológica a essa fonte epistêmica. Ou seja, a percepção ser, em geral, uma condição para o testemunho não implica, de fato, que o status epistêmico do testemunho não seja original. E, para ele, na verdade, ainda há algo de enganador nessa concessão de uma centralidade à percepção, pois é impossível tratar essas quatro fontes de conhecimento como se fossem completamente isoladas umas das outras, pois há grau de interpenetração entre todas elas. E se não há percepção que não esteja contaminada pelo testemunho, memória e/ou inferência, então a ideia de fazer da percepção pura algum tipo de pedra fundamental epistemológica para qualquer ou para todas as outras três fontes é absurda.

E, no entanto, apesar da afirmação exaustiva dessa suposta superioridade epistemológica para a percepção, existe uma abundância de casos em que o nosso veredito pode perfeitamente ir contra a percepção, por exemplo:

Jones 'vê' um velho amigo no final do corredor e depois diz aos outros que o viu, mas depois lhe é dito que esse amigo não poderia estar no prédio porque viajou dois dias antes para o estrangeiro. Antes de receber esta informação Jones pode ter sido totalmente convencido, com base na visão, que viu seu amigo, mas há seguramente circunstâncias em que tal convicção é racionalmente minada pelo testemunho dos outros (COADY, 1992, p. 148, tradução nossa).

Para ele, essa discussão mostra que o anseio por uma primazia da percepção é um anseio por uma primazia da percepção do próprio indivíduo, e essa suposição só tem algum apelo porque assume o tipo de problema egocêntrico que constitui um natural ponto de partida para uma epistemologia ou para um ceticismo muito mais tradicional. É preciso, então, questionar esse ponto de vista e assumir a importância e credibilidade do testemunho como uma fonte epistêmica, a partir da qual adquirimos conhecimento.

4 Outras respostas ao reducionismo epistemológico 


\subsection{A visão disjuntiva de Jennifer Lackey}

Lackey é uma das estudiosas da revolução externalista, ela defende no seu livro Learning from Words: Testimony as a Source of Knowledge que boa parte do recente interesse na epistemologia do testemunho tem sido moldado e guiado por uma tese que é quase universalmente aceita, a tese da transmissão, segundo a qual "o conhecimento é adquirido através do testemunho quando os oradores transmitem suas crenças, juntamente com as propriedades epistêmicas que elas possuem, para seus ouvintes correspondentes" (LACKEY, 2008, p. 1, tradução nossa). De acordo com essa tese, os ouvintes podem adquirir conhecimento a partir do testemunho de oradores apenas se os próprios oradores possuem o conhecimento em questão. No entanto, apesar do enorme apelo intuitivo dessa tese, Lackey argumenta que existem várias maneiras por meio das quais os ouvintes podem adquirir conhecimento testemunhal a partir de oradores que não possuem o conhecimento em questão, demonstrando assim que a tese da transmissão está fundamentalmente equivocada.

Lackey, diferente de outros autores, se concentra nos itens linguísticos ou comunicativos dos intercâmbios testemunhais, tais como declarações e outros atos de comunicação. O resultado de seu posicionamento é que, a rigor, "nós não aprendemos a partir dos estados de crer ou saber de outra pessoa, mas aprendemos com as palavras de outras pessoas" (LACKEY, 2008, p. 2, tradução nossa). A autora, assim como Coady, está preocupada em definir o testemunho como uma fonte de crença, para além da percepção sensorial, da memória, da razão e da introspecção, fonte essa pela qual os ouvintes adquirem informações a partir da palavra falada ou escrita dos outros.

Analisando o papel específico desempenhado pelo ouvinte nos intercâmbios testemunhais, ela se questiona se a fim de adquirir conhecimento a partir do testemunho de um orador, é suficiente, como os não-reducionistas defendem, que o ouvinte simplesmente não possua razões negativas para confiar no relato confiável de um orador ou, como os reducionistas defendem, o ouvinte também precisa possuir razões positivas para confiar no orador. Assim, o testemunho seria ou uma fonte irredutível do conhecimento ou redutível a fontes mais básicas de conhecimento. Para Lackey, ambas as respostas são inadequadas e razões positivas são necessárias para o conhecimento testemunhal, mas o testemunho em si é uma fonte irredutível de conhecimento. Isso leva ao desenvolvimento de sua visão dualista, segundo a qual "a fim de adquirir conhecimento testemunhal, tanto o orador quanto o ouvinte 
devem fazer uma contribuição epistêmica positiva para o conhecimento em questão, o primeiro pela confiabilidade de sua declaração e o último através de suas razões positivas" (LACKEY, 2008, p. 2, tradução nossa).

Preocupada com a questão prévia do que é precisamente o testemunho, Lackey analisa e critica alguns dos mais importantes pontos de vista da bibliografia sobre o assunto. Ela argumenta que a visão de Coady sobre a natureza do testemunho é estreita, e pode ser apresentada da seguinte maneira:

Visão Estreita da Natureza do Testemunho (VENT): S testemunha através de alguma declaração de que $\mathrm{p}$ se e somente se:

1) S declarar que $\mathrm{p}$ é evidência de que $\mathrm{p}$ e é oferecido como evidência de que $\mathrm{p}$.

2) S tem competência, autoridade ou credenciais relevantes para declarar verdadeiramente que $\mathrm{p}$.

3) A declaração de $S$ de que p é relevante para alguma disputa ou questão não resolvida (que pode ou não ser sobre p) e é direcionada para aqueles que necessitam de evidências sobre o assunto (LACKEY, 2008, p. 15, tradução nossa).

Segundo Lackey, tal visão permite que um orador faça uma declaração que não satisfaça todas as três condições de VENT, mas apesar disso sua declaração não deixa de ser testemunhal. Por exemplo, uma declaração, apesar de oferecida como evidência, pode não ser evidência potencial; o orador pode não ter a competência, autoridade ou credenciais relevantes para declarar verdadeiramente que p; sua declaração pode não ser relevante para alguma questão em disputa ou não resolvida e não ser dirigida a um ouvinte que necessita de evidências sobre o assunto. Ela afirma que Coady falha tanto em reconhecer o sentido em que o testemunho pode ser uma fonte de crença ou de conhecimento para um ouvinte, independentemente da intenção do orador em ser uma fonte epistêmica, quanto em reconhecer o sentido em que um orador pode testemunhar, independentemente das necessidades ou interesses epistêmicos de seus ouvintes. VENT requer a conjunção das intenções do orador com as necessidades do ouvinte, e por isso é estreita demais.

Em seguida, analisa outra visão muito considerada na bibliografia e que, para ela, é ampla demais. Essa é a visão de Elizabeth Fricker, Robert Audi, Ernest Sosa e outros autores. Para eles, o domínio do testemunho que é de interesse epistemológico é o dos dizeres em geral, sem restrições, e que exige apenas que seja uma declaração de pensamentos ou crenças de alguém, que podem ser direcionadas para o mundo em geral ou para ninguém em particular. Ou seja, esses autores entendem, resumidamente, um dizer como uma expressão dos pensamentos de alguém. Lackey caracteriza tal visão da seguinte maneira: "Visão Ampla 
da Natureza do Testemunho (VANT): $\mathrm{S}$ testemunha que $\mathrm{p}$ se e apenas se a declaração de $\mathrm{S}$ de que p é uma expressão do pensamento de S de que p" (LACKEY, 2008, p. 20, tradução nossa).

Para Lackey, essa visão mais ampla evita os problemas apresentador por VENT, porém, ela também apresenta problemas. VANT falha em reconhecer a distinção entre expressões completamente não informativas do pensamento e testemunho, como meramente expressar "Ah, que belo dia!” para alguém que está ao seu lado. Se adotarmos tal visão, então qualquer expressão do pensamento acaba por ser um exemplo de testemunho e esse é, claramente, um resultado inaceitável.

Continuando sua análise das visões encontradas na literatura, ela afirma que precisamos de uma consideração de testemunho que seja mais ampla que VENT e mais restritiva que VANT, e assim apresenta e analisa a visão moderada de Peter Graham. De acordo com a qual:

Visão Moderada da Natureza do Testemunho (VMNT): S testemunha ao fazer alguma declaração de que $\mathrm{p}$ se e apenas se:

1) A declaração de $S$ de que $p$ é oferecida como uma evidência de que $p$.

2) S pretende que o seu público acredite que ele tem a competência, autoridade e credenciais relevantes para afirmar verdadeiramente que $\mathrm{p}$.

3) A declaração de $\mathrm{S}$ de que $\mathrm{p}$ é acreditada por $\mathrm{S}$ como sendo relevante para alguma questão em disputa ou não resolvida e é direcionada àqueles a quem $\mathrm{S}$ acredita necessitarem de evidências sobre o assunto (LACKEY, 2008, p. 23, tradução nossa).

Graham evita os problemas levantados contra VENT, uma vez que requer apenas que S pretenda que a sua audiência acredite que ele tem as credenciais relevantes para declarar verdadeiramente que $\mathrm{p}$, ao invés de afirmar que as tem e requer apenas que $\mathrm{S}$ acredite que há uma questão não resolvida, ao invés de havê-las, e assim os oradores podem testemunhar independentemente das necessidades do ouvinte. Evita também o problema de VANT, uma vez que coloca restrições nos tipos de declarações oferecidas, pois um orador oferece sua declaração como evidência de que $\mathrm{p}$, acredita que $\mathrm{p}$ é relevante e direciona sua declaração para aqueles que necessitarem de evidência. Porém, em contrapartida, tal visão exige várias intenções e crenças por parte do orador. E também cai num dos problemas de VENT, pois não consegue captar o sentido em que o testemunho pode ser uma fonte de crença ou conhecimento para um ouvinte independentemente da intenção do orador em ser tal fonte.

Tendo diagnosticado problemas nessas visões, Lackey afirma que o nosso conceito de testemunho tem uma natureza dual, visto que parece haver dois aspectos distintos e, muitas 
vezes, independentes em tal noção. Por um lado, o testemunho é frequentemente pensado como um ato intencional por parte do orador. Por outro lado, no entanto, o testemunho é frequentemente pensado como simplesmente uma fonte de crença ou conhecimento para o ouvinte, não dependendo das intenções do orador, mas sim das necessidades do ouvinte. Focada no amplo conceito de um ato de comunicação, que não requer que o orador pretenda comunicar os outros, mas apenas que o orador pretenda expressar um conteúdo comunicável, ela distingue dois conceitos de testemunho: testemunho do orador (ora-testemunho) e testemunho do ouvinte (ouv-testemunho). A distinção se apresenta da seguinte maneira:

Ora-testemunho: $S$ ora-testemunha que $\mathrm{p}$ realizando um ato de comunicação A se e apenas se, na realização de A, S razoavelmente pretende transmitir a informação de que $\mathrm{p}$ em virtude do conteúdo comunicável de A” (LACKEY, 2008, p. 30, tradução nossa).

Ouv-testemunho: $\mathrm{S}$ ouv-testemunha que $\mathrm{p}$ realizando um ato de comunicação A se e apenas se $\mathrm{H}$, o ouvinte de $\mathrm{S}$, razoavelmente toma A como transmitindo a informação de que $\mathrm{p}$ em virtude do conteúdo comunicável de A (LACKEY, 2008, p. 32, tradução nossa).

Estando consciente dessa característica dual, ela propõe sua própria visão sobre a natureza do testemunho, uma que resolveria os problemas apresentados pelas visões anteriores e captaria esse sentido dual da natureza do testemunho, de acordo com a qual:

Visão Disjuntiva da Natureza do Testemunho (VDNT): $\mathrm{S}$ testemunha que $\mathrm{p}$ realizando um ato de comunicação $\mathrm{A}$ se e apenas se, em virtude do conteúdo comunicável de A, (1) S razoavelmente pretende transmitir a informação de que p ou (2) A é razoavelmente tomado como transmitindo a informação de que p (LACKEY, 2008, 35-36, tradução nossa) ${ }^{2}$.

\subsection{O comunitarismo de Martin Kusch}

Martin Kusch afirma que pertence à minoria que acredita que alguns dos desafios mais importantes para a filosofia atualmente vêm da sociologia do conhecimento e que pretende mostrar como a epistemologia deve mudar, se quiser fazer justiça ao que é significativo na insistência dos sociólogos de que o conhecimento é uma instituição social. Ele denomina seu projeto, exposto no seu livro Knowledge by Agreement: The Programme of Communitarian Epistemology, de programa de epistemologia comunitária, onde o comunitarismo significa

\footnotetext{
${ }^{2}$ Sendo que esse ou não é exclusivo, ambos (1) e (2) podem ser satisfeitos simultaneamente.
} 
que a comunidade é, na ordem de explicação, anterior ao individual, e também que indivíduos morais não precedem comunidades morais e só podem ser compreendidos através de sua participação em comunidades morais.

Entretanto, a epistemologia comunitária contrasta com as posições mais tradicionais e contemporâneas na epistemologia. De acordo com Kusch, seus opositores não conseguem reconhecer o conhecimento como um status social, e pensam o conhecimento como de posse primária de indivíduos e não de grupos. Para tais formas individualistas de epistemologia, o conhecimento é social apenas na medida em que é transmitido de um indivíduo para outro. Como o objetivo de Kusch é introduzir o comunitarismo na epistemologia, ele precisa explicar porque as pessoas podem conhecer apenas na medida em que elas são membros de comunidades epistêmicas e este esforço envolve identificar e exorcizar o individualismo epistemológico.

Outro ponto abordado por Kusch diz respeito à questão da nossa adoção de crenças baseadas no testemunho ser inferencial, quando envolve inferências que contenham premissas sobre a competência e honestidade das testemunhas, ou direta, quando acontece sem tais premissas e inferências. Ele expõe o trabalho de Elizabeth Fricker, a defensora mais conhecida do inferencialismo, que sustenta que o destinatário adulto normal do testemunho forma uma teoria psicológica do orador, e que os julgamentos de confiança sobre o orador são parte de tal teoria. Ela também especula sobre como formamos nossas crenças sobre a confiabilidade dos oradores e "assume que costumamos tratar a confiabilidade como a posição padrão, mas que sempre monitoramos oradores para denunciar sinais de desonestidade e incompetência" e "que o monitoramento de sinais reveladores de falta de sinceridade e incompetência normalmente ocorre subconscientemente" (KUSCH, 2002, p. 23, tradução nossa). Em contrapartida, ele apresenta a visão direta do testemunho, que é abordada por autores como Anthony Coady, Michael Dummett, John McDowell e Peter Strawson, entre outros. Coady, por exemplo, afirma que "nas nossas relações normais com os outros nós reunimos informação sem essa preocupação de inferir a aceitabilidade das comunicações a partir de premissas sobre a honestidade, confiabilidade, probabilidade, etc., dos nossos comunicantes" (COADY, 1992, p. 143, tradução nossa). Para Coady, apesar de sermos obrigados a suspender a crença quando temos razão para desconfiar, não há dever geral de vigilância do orador para sinais reveladores de falta de sinceridade e incompetência. 
De acordo com Kusch, ambos estão parcialmente certos e parcialmente errados. Para ele, à primeira vista, o problema central na discórdia entre Coady e Fricker parece se concentrar no dever de monitoramento, mas, na verdade, o que divide Coady e Fricker não é tanto a diferença entre monitoramento e não monitoramento, mas sim "a oposição entre monitoramento ativo e passivo" (KUSCH, 2002, p. 26, tradução nossa). Segundo ele, Fricker parece confiar na ideia de que só é possível detectar algo, caso se tenha monitorado ativamente para isso, porém há muitas coisas que eu posso perceber sem qualquer monitoramento ativo, sendo que:

no caso do testemunho: detectar ou notar que alguém está mentindo para nós, provavelmente, não pressupõe que alguém foi monitorado ativamente para essa possibilidade. É suficiente que algo que ouvimos ou lemos não se encaixe em nossas crenças nos outros sobre o assunto, a situação, ou o orador. Isto é, nossas crenças anteriores podem ser uma função de filtro para as coisas que nos são contadas. Mas os filtros não são dispositivos de monitoramento ativo, eles são passivos (KUSCH, 2002, p. 26, tradução nossa).

Já em relação à justificação testemunhal, discussão essa que se dá no embate entre os reducionistas e os fundamentalistas, a epistemologia comunitária de Kusch não apenas se opõe ao reducionismo, mas também rejeita as justificativas não-reducionistas ou fundamentalistas de testemunho ${ }^{3}$. Ao invés de escolher entre uma dessas opções, Kusch opta pelo quietismo, visão de que as justificativas globais de testemunho são impossíveis, e pelo contextualismo, tese de que toda justificação é local e contextual. Para ele, acreditar que o testemunho precisa de uma justificativa geral é em si uma expressão do individualismo, tudo o que podemos justificar é a nossa confiança em informantes específicos em determinadas circunstâncias. Como o objetivo de Kusch é mostrar que o testemunho constitui de fato os padrões de mudança de justificação, que os padrões de justificação são convencionais, ou seja, são instituições sociais, e que todas as instituições sociais são criadas e mantidas pela comunicação, então o quietismo e o contextualismo são as únicas posições corretas relativas à justificação do testemunho.

3 Vale ressaltar que apesar de discordar das justificativas testemunhais não-reducionistas, Kusch, assim como os não-reducionistas, defende que o testemunho é uma fonte geradora de conhecimento. 


\subsection{O Confiabilismo de Goldberg}

Goldberg é mais um autor que defende que o fato de que dependemos dos outros para muito do que sabemos sobre o mundo deve levar a uma reconsideração das orientações individualistas da epistemologia tradicional. Ele propõe em sua obra Relying on Others: an Essay in Epistemology, que tal reconsideração se dê a partir do confiabilismo. Porém, ele mesmo reconhece que essa é uma escolha curiosa, tendo em vista que a maioria das versões do confiabilismo permanecem altamente individualistas em sua orientação, pois defendem que os processos de formação de crenças relevantes ocorrem dentro do cérebro/mente do sujeito que acredita. Goldberg usa o termo confiabilismo ortodoxo como um rótulo para qualquer versão confiabilista que apoie esta hipótese do individualismo processual de que o que torna algo conhecimento tem a ver com a confiabilidade do(s) tipo(s) de processo(s) ou método(s) através do qual uma crença é formada ou sustentada. Ou seja, o fato de uma crença testemunhal ser considerado como conhecimento testemunhal depende da confiabilidade do testemunho no qual se baseou, que por sua vez depende da confiabilidade dos processos cognitivos envolvidos na produção do testemunho. E se isto está correto, então na medida em que a aquisição de conhecimento testemunhal depende dos recursos de confiabilidade do testemunho consumido, então depende das características de confiabilidade do processamento cognitivo na mente/cérebro do falante. Goldberg afirma que seu objetivo é libertar a epistemologia confiabilista das garras dessa ortodoxia.

Ele começa afirmando que os confiabilistas processuais que endossam o individualismo processual têm um forte motivo para adotar a concepção tradicional da relevância epistêmica do testemunho. Pois, se a confiabilidade de um pedaço de testemunho é uma questão da confiabilidade do processo cognitivo através do qual o testemunho é produzido, e se esses processos ocorrem dentro da própria mente/cérebro da fonte oradora e por isso são externos ao equipamento de processamento de informações do ouvinte, então, pelas luzes do individualismo processual, eles são "externos" aos processos cognitivos através dos quais a crença testemunhal é produzida. Mas, de acordo com o confiabilismo processual, justificação doxástica é uma questão de confiabilidade dos processos cognitivos, que são responsáveis pela produção da crença. Conclui-se disso que os fatos sobre a confiabilidade do testemunho, incluindo fatos sobre a confiabilidade dos processos que produziram o testemunho, são irrelevantes para a justificação da crença doxástica testemunhal resultante. E 
aqui reside a pressão que os confiabilistas ortodoxos sofrem para abraçar a concepção tradicional de importância epistêmica, pois na medida em que admitem que os fatos sobre a confiabilidade de um testemunho têm alguma importância epistêmica, devem considerar essa importância como restrita a uma característica do ambiente local do sujeito. E essa é a hipótese da confiabilidade local.

Goldberg acredita, no entanto, que essa visão é a expressão de uma concepção fundamentalmente errada de importância epistêmica do testemunho e nega a necessidade desse compromisso do confiabilista ortodoxo para com a concepção tradicional de importância epistêmica do testemunho e para com a hipótese da confiabilidade local. Para ele, "a concepção tradicional não se enquadra com o que ele chama de 'natureza crençadependente de formação de crenças testemunhais" (GOLDBERG, 2010, p. 57, tradução nossa). Mais concretamente, ele defende que os confiabilistas processuais estão bem aconselhados em repudiar o individualismo processual, pois, afinal de contas, é o compromisso com o individualismo processual que força o confiabilista processual a endossar tanto a concepção tradicional quanto a hipótese da confiabilidade local. Para Goldberg, assim que o confiabilista processual estiver livre de qualquer compromisso, ele "poderá ver o processo cognitivo envolvido na produção do testemunho do orador, e não como aspectos do ambiente meramente local do ouvinte, mas sim como parte do próprio processo de formação de crença testemunhal" (GOLDBERG, 2010, p. 57, tradução nossa). Essa hipótese estendida, como ela a chama, é o aspecto mais abrangente da nossa confiança epistêmica sobre os outros.

Em seguida, focado no tema da justificação doxástica, Goldberg considera uma das ideias centrais do cConfiabilismo sobre a justificação: a relevância dos recursos históricos para as avaliações epistêmicas de justificação doxástica. Nisso ele está seguindo o também confiabilista Alvin Goldman, defensor do confiabislismo histórico, segundo o qual o status de justificação de uma crença dependerá da sua história anterior e enfatiza a confiabilidade dos processos de geração dessa crença, em contraste com abordagem dominante da crença justificada conhecida como confiabilismo fase terminal, segundo a qual o status de justificação de uma crença é uma função do que é verdadeiro para o conhecedor no momento da crença. Tanto Goldman quando Goldberg defendem que a orientação individualista do confiabilismo ortodoxo é culpada por endossar uma espécie de confiabilismo fase terminal em relação à crença testemunhal. 
Parte do que Goldberg quer sugerir é que confiabilistas processuais têm um bom motivo para se interessarem nas práticas sociais e instituições, uma vez que algumas destas afetam a confiabilidade dos nossos processos de formação de crença (por exemplo, nos casos de testemunhos quando os próprios fatores sociais constituem parte do processo de formação de crença). Para ele, os fatores sociais afetam as avaliações de confiabilidade e, com efeito, é preciso socializar a confiabilidade, e ao fazer isso reconhecer que a epistemologia confiabilista é uma epistemologia social.

\section{Conclusão}

Tendo em vista a discussão apresentada, é possível observar que praticamente todas as visões contemporâneas a respeito do testemunho consideram este, finalmente, como uma das mais importantes fontes epistêmicas a partir da qual podemos adquirir conhecimento, indo contra toda a tradição de negligência e preconceito que dominou o campo de investigação testemunhal na epistemologia durante muito tempo.

O testemunho conseguiu impor seu status e importância epistêmica, e, com isso, abriu um enorme campo de investigação epistemológica que apesar de tão rico ainda foi muito pouco explorado. Em relação à justificação testemunhal, por exemplo, existem diversas tentativas de respostas que divergem entre si. O que salta aos olhos no que diz respeito à justificação testemunhal, no entanto, é que apesar de ainda existirem orientações reducionistas e elas ainda possuírem seu lugar dentro da epistemologia, cada vez mais as tentativas de justificar o testemunho têm caminhado em direção a uma externalização e socialização do testemunho. A partir do momento em que negamos que o individualismo relativo ao testemunho é defensável, estamos orientando a epistemologia em direção ao social e exercendo a verdadeira revolução externalista.

Porém, é necessário também não esquecer o papel do indivíduo cognoscente e lembrar que, se quisermos ter um quadro epistemológico muito mais amplo e completo, precisamos tanto considerar os aspectos individuais quanto os aspectos sociais envolvidos na aquisição e transmissão de conhecimento, só assim estaremos mais perto de conseguir entender e justificar como funcionam as diferentes formas de adquirir conhecimento, ou se é possível que exista tal forma de justificação. 


\section{REFERÊNCIAS BIBLIOGRÁFICAS}

COADY, C. A. J. Testimony: A Philosophical Study. Oxford: Oxford University Press, 1992.

GOLDBERG, Sanford C. Relying on Others: An Essay in Epistemology. Oxford: Oxford University Press, 2010.

HUME, David. Investigações sobre o Entendimento Humano e sobre os Princípios da Moral. Tradução de José Oscar de Almeida Marques. São Paulo: Editora UNESP, 2004.

KUSCH, Martin. Knowledge by Agreement: The Programme of Communitarian Epistemology. Oxford: Oxford University Press, 2002.

LACKEY, Jennifer. Learning from Words: Testimony as a Source of Knowledge. Oxford: Oxford University Press, 2008. 